\title{
Analysis of radiation-induced bystander effects using high content screening
}

\author{
$\underline{\text { B. Dieriks }}^{1}$, W. De $\operatorname{Vos}^{1}$ and P. Van Oostveldt ${ }^{1}$ \\ 1. Molecular Biotechnology, Cell biology and Molecular Cytology, Faculty of Bio- \\ engineering University Ghent, Coupure Links 653, 9000, Belgium
}

birger.dieriks@ugent.be

Keywords: $\gamma \mathrm{H}_{2} \mathrm{AX}$, bystander effect, high content screening

When cells are exposed to (ionising) radiation there is a rapid phosphorylation of a minor nucleosomal histone protein, $\mathrm{H}_{2} \mathrm{AX}$, at the sites where double stranded breaks (DSB) occur. This phosphorylation is one of the earliest events in the repair cascade and extends over several mega base pairs surrounding the break. Nowadays it is generally accepted that the formation of $\gamma \mathrm{H}_{2} \mathrm{AX}$ functions as a signal enhancer. Using immuno histochemistry we can visualise this phosphorylation as foci in the nucleus, where each foci represents a DSB [1].

For our research we use normal human primary fibroblasts (NHDF's) to study the so called radiation-induced bystander effects which refer to the responses induced in nonirradiated cells, when neighbouring cells are irradiated. Although the exact pathways of transmission are yet to be determined, studies have shown that gap junction-mediated transport and secretion of soluble extracellular factors play an important role [2].

To exclude variation we first tried synchronisation of the fibroblasts using nocodazole or aphidicolin. Our attempts did not produce the desired synchronisation level. In addition, recent reports doubt the effectiveness of these products in cell synchronisation [3]. To resolve this problem, we used high content screening of cells together with specific cell cycle markers. One of these markers is 5-bromo-2deoxyuridine (BrdU). BrdU, a synthetic nucleoside, is an analogue of thymidine that can be incorporated in replicating cells and specifically label S-phases [4].

Cells are cultured on membrane inserts, with a pore size of $0,4 \mu \mathrm{m}$ allowing soluble factors to pass but preventing the cells to interchange. These cells are irradiated with different doses and subsequently placed together with NHDF that are grown on cover glasses (see figure 1). Depending on the objectives BrdU is added 20-40 minutes before fixation.

We found a differential pattern for $\gamma \mathrm{H}_{2} \mathrm{AX}$ that we could specifically link to the cell cycle. During the $\mathrm{S}$ phase $\gamma \mathrm{H}_{2} \mathrm{AX}$ is significantly more induced than during other phases of the cell cycle (see figure 2). This is probably due to the increased vulnerability caused by the unwinding of DNA during replication.

1. S.H.Macphail, J.P.Banath, T.Y.Yu, E.H.Chu, H.Lambur, P.L.Olive, Int.J.Radiat.Biol. 79 (2003) P. 351-358.

2. H.Yang, N.Asaad, K.D.Held, Oncogene 24 (2005) p. 2096-2103.

3. S.Cooper, G.Iyer, M.Tarquini, P.Bissett, Cell Tissue Res. 324 (2006) p.237-242.

4. R.T.O'Keefe, S.C.Henderson, D.L.Spector, J.Cell Biol. 116 (1992) p.1095-1110. 

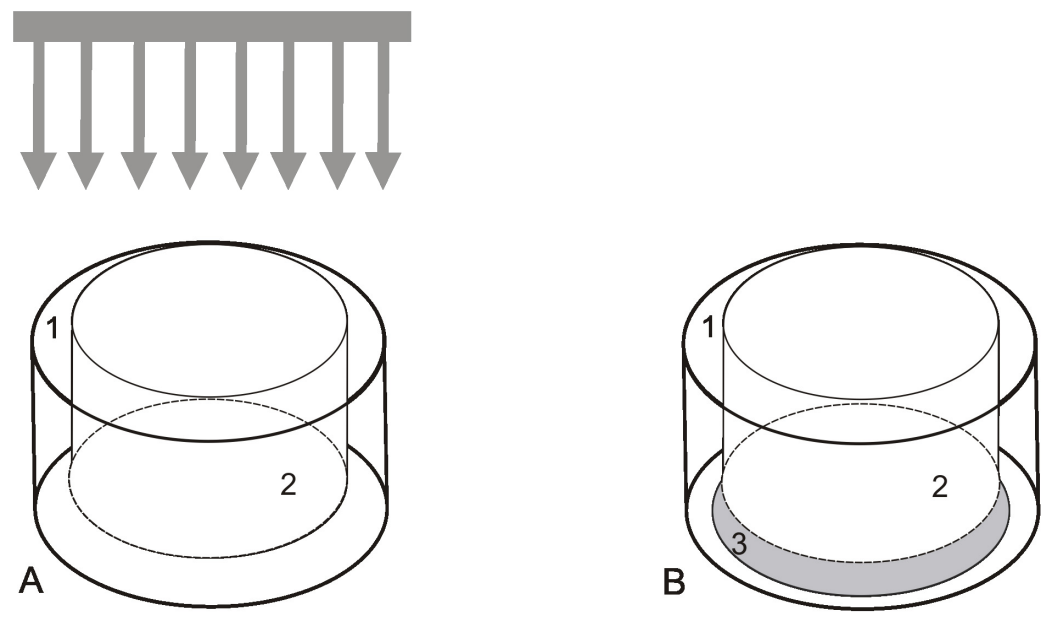

Figure 1. experimental setup A: NHDF's are cultured in a 12 well plate (1) on membrane inserts (2) and subsequently irradiated at ambient temperature with $250 \mathrm{kV}$ $\mathrm{X}$-rays, $13 \mathrm{~mA}$ and $1 \mathrm{~mm} \mathrm{Cu}$ filter. $\mathrm{B}$ : The membrane inserts were transferred to a new well so that they would be in close proximity with non-irradiated NHDF's on cover slips (3)

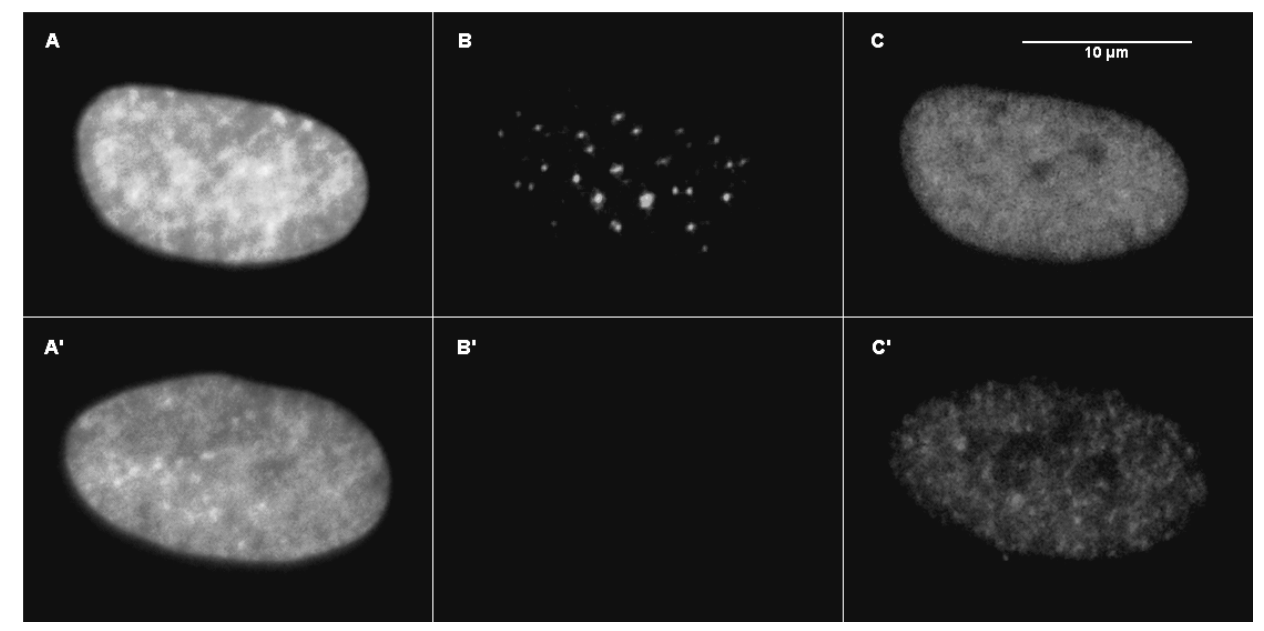

Figure 2. Immunostaining of NHDF pulsed labelled with $20 \mu \mathrm{M}$ BrdU for $20 \mathrm{~min}$ followed by $15 \mathrm{~min} \mathrm{UV}$ irradiation. DAPI, BrdU, $\gamma \mathrm{H}_{2} \mathrm{AX}$ in an $\mathrm{S}$ phase (respectively $\mathrm{A}$, $\mathrm{B}$ and $\mathrm{C}$ ) and a non $\mathrm{S}$ phase cell (A', B' and $\mathrm{C}^{\prime}$ ). 